Simone de Macedo Amaral ${ }^{1}$ Águida Maria Menezes Aguiar Miranda ${ }^{2}$

Juliana de Noronha Santos

Netto $^{3}$

Fábio Ramôa Pires ${ }^{4}$

\section{Prevalence of oral and maxillofacial diseases diagnosed in an Oral Medicine service during a 7-year period}

\begin{abstract}
:
Prevalence of oral and maxillofacial diseases is highly variable depending on the region, country and source of the data. The aim of this study was to determine the prevalence of oral and maxillofacial diseases diagnosed in an Oral Medicine service during a 7-year period. All clinical charts from patients attending the service in the period were reviewed to retrieve demographic and clinical data; diagnosis were classified in groups, distributed in absolute and relative values and analyzed with respect to their frequency. A total of 1075 clinical charts were reviewed and females represented $60 \%$ of the sample. Mean age of the patients was 41 years (ranging from 1 month to 94 years old) and most patients were in their fourties to fifties. A total of 1444 oral diseases were diagnosed and the most prevalent groups were soft-tissue tumors (184 cases, 12.7\%), developmental defects $(161,11.2 \%)$ and epithelial diseases $(127,8.8 \%)$. Individually, the most frequent diseases included fibrous hyperplasias (120 cases, $8.3 \%)$, candidosis $(77,5.3 \%)$, periradicular inflammatory lesions $(72,5.0 \%)$ and potentially malignant disorders $(52,3.6 \%)$. Oral carcinomas represented $2.5 \%$ of the sample (36 cases). The present results reflect the frequency of oral diseases diagnosed in a specialized service in southeastern Brazil and will allow the establishment of preventive strategies and the adequacy of the clinical services offered to the target population.
\end{abstract}

Keywords: disease; epidemiology; mouth; oral medicine.
${ }^{1}$ DDS, MSc, Post-graduation Program in Dentistry, Estácio de Sá University, Rio de Janeiro, Brazil (Oral Medicine, Brazilian Dental Association, Rio de Janeiro, Brazil).

${ }^{2}$ DDS, MSc, Stomatology and Oral Surgery, Estácio de Sá University, Rio de Janeiro, Brazil (DDS, MSc, Stomatology and Oral Surgery, Estácio de Sá University, Rio de Janeiro, Brazil). ${ }^{3}$ DDS, MSc, Oral Medicine, Brazilian Dental Association, Rio de Janeiro, Brazil (DDS, MSc, Oral Medicine, Brazilian Dental Association, Rio de Janeiro, Brazil).

${ }^{4}$ DDS, PhD, Post-graduation Program in Dentistry, Estácio de Sá University, Rio de Janeiro, Brazil (DDS, PhD, Post-graduation Program in Dentistry, Estácio de Sá University, Rio de Janeiro, Brazil).

Declaration of Interests: The authors certify that they have no commercial or associative interest that represents a conflict of interest in connection with the manuscript.

Corresponding Author:

Fábio Ramôa Pires.

E-mail: ramoafop@yahoo.com

DOI: 10.5935/2525-5711.20160002

Submitted: July 15, 2012;

Accepted: August 27, 2012.

Originally published as 1 (2) April/June 2012 


\section{INTRODUCTION}

Studies reporting on the prevalence of oral diseases in different countries from all continents have been reported in the literature in a regular basis in the last years ${ }^{1-6}$. They are essential in highlighting epidemiologic, geographic and racial biases and similarities among different populations, offering the possibility of comparing health service needs in different countries and regions. In large countries, such as Brazil, even local economic, cultural and social differences, for example, can affect the prevalence of oral diseases in specific regions.

Most reports have focused on the prevalence of oral and maxillofacial diseases in specific groups, including only soft-tissue lesions, lesions from a specific anatomic location, lesions from a specific age group, lesions diagnosed in oral and maxillofacial surgical pathology laboratories, lesions diagnosed in convenience samples and lesions diagnosed in population-based studies ${ }^{1-6}$. Although all studies have their specific and individual importance when studying the epidemiology of oral diseases, they do not reflect the real incidence of oral lesions in a regular Stomatology service. For this reason, the aim of this study was to report the prevalence of oral and maxillofacial diseases diagnosed in consecutive patients attending on an Oral Medicine service during a 7-year period.

\section{MATERIALS AND METHODS}

This is a descriptive cross-sectional retrospective study based on data from the clinical records of consecutive patients attending the Stomatology clinic, Dental School, Estácio de Sá University, Rio de Janeiro, Brazil, from january 2003 to december 2008. Demographic (gender and age) and clinical (anatomical location of lesions, biopsies or other diagnostic procedures and final diagnosis) data were retrieved from the clinical charts from each individual patient. Patients whose clinical charts were not found at the time of the review were excluded from the study.

Final diagnosis included the chief complaint (or complaints) of the patients at first consultation and also any other oral and maxillofacial disease diagnosed without being noticed by the patients at first consultation. Developmental defects of the oral and maxillofacial region (for example, Fordyce spots, geographic tongue and fissured tongue) were only included as final diagnosis if they represented a complaint for the patients, not if they were observed only during clinical examination. Oral recurrent conditions, such as recurrent aphthous stomatitis and recurrent herpetic infections, were only considered as final diagnosis if clinical examination revealed oral and maxillofacial lesions present at the time of examination; if the patients solely reported history of past lesions, this was not considered as final diagnosis. Final diagnosis included both clinical diagnosis (when history, clinical features and eventually clinical laboratory and imaginological exams where sufficient for correct diagnosis) and surgical pathology diagnosis (when conventional biopsies or fine-needle aspiration biopsies were indicated).

Apart from the oral cavity (up to oropharynx), other anatomic locations included submandibular, submental, parotid, masseteric, mandible, maxilla (including maxillary sinus) and perioral lymph nodes. Large lesions involving more than one region were classified into their central anatomic location and diseases affecting more than one location simultaneously where classified in all affected areas. Conditions affecting lymph nodes and minor salivary and sebaceous glands were classified in the anatomical region where they were located.

The classification proposed by a worldwide accepted oral and maxillofacial pathology compendium ${ }^{7}$ was used, whenever possible, for nomenclature and classification of the diseases. Although this reference covered most oral and maxillofacial lesions, some minor modifications and adjustments were necessary and were performed according to the most recent concepts in oral and maxillofacial pathology. Apart from the 18 disease groups established by this reference, two other groups were included: other diseases (other developmental, inflammatory and infectious diseases not included in other groups and conditions with inconclusive diagnosis) and no lesions (no disease diagnosed at examination).

Oral and maxillofacial conditions diagnosed in the sample were quantified in absolute numbers and percentages within each group, the most frequent groups being compared with the total number of cases and according to age group distribution. The most frequent individual diseases were also quantified in separate. Data obtained on the overall prevalence of the diseases in the sample and the most commonly diagnosed conditions were compared with those reported on the literature, searching for differences and similarities between studies and populations.

This study was approved by the Ethics Committee, Estácio de Sá University (number CAAE - 0121.0.308.000-09).

\section{RESULTS}

A total of 1075 consecutive patients attended the Stomatology service, Dental School, Estácio de Sá University, from january 2003 to december 2008. Gender distribution showed 646 females (60.1\%) and 429 males (39.9\%). Mean age of the patients was 41 years-old (ranging from 1 month to 94 years), and mean age for males was 43 years-old (ranging from 1 month to 86 years) and for females was 40 years-old (ranging from 1 month to 94 years). From the 646 females, 146 (22.6\%) were 60 years or older, while for the 429 males, 77 (17.9\%) were in this age group. The most frequent decade for males was the $3^{\text {rd }}$ 
decade and for females was the $5^{\text {th }}$ decade. The sample consisted of 183 patients (17\%) in the first two decades of life, from which $96(52.5 \%)$ were males and 87 (47.5\%) females (Figure 1).

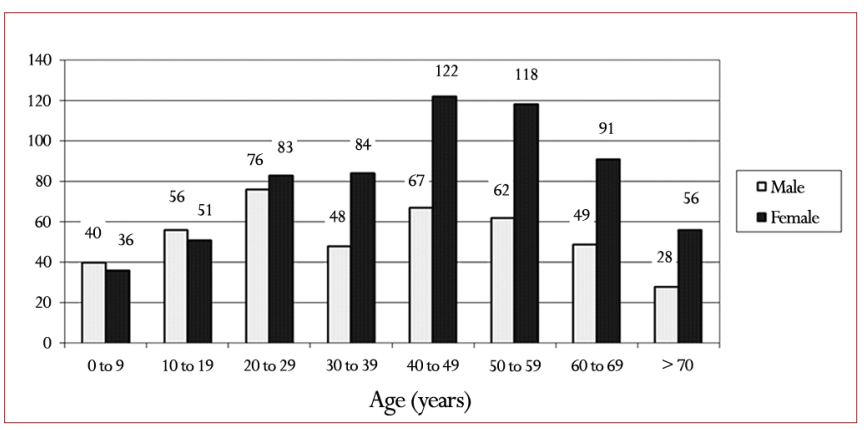

Figure 1. Distribution of the 1067 patients by gender and age (in years). Age information was not available for 8 patients.

From the 1075 patients studied, 1444 oral and maxillofacial final diagnosis were reviewed, with a mean of 1.3 diagnosis per patient. Most patients $(774,72 \%)$ presented only one condition, 205 (19\%) showed two conditions, 58 (5.4\%) three conditions, $19(1.8 \%) 4$ conditions, $2(0.2 \%)$ showed 5 conditions, and $17(1.6 \%)$ patients presented with no lesions. From the 1075 patients, 544 (50.6\%) were submitted to biopsies and other surgical procedures or fine-needle aspiration biopsies for final diagnosis.

Tumors of soft tissues represented the most frequent group (184 cases, $12.7 \%)$, followed by developmental defects $(161,11.2 \%)$, epithelial pathology $(127,8.8 \%)$, diseases of the salivary glands $(125,8.6 \%)$ and physical and chemical injuries $(105,7.3 \%)$. Although all disease groups were more common in adults in the sample, the percentage of affected patients in the first two decades of life ranged from zero (Fungal and protozooal infections and Hematological disorders) to $40 \%$ (Odontogenic cysts and tumors and Bacterial infections) (Table 1).

When individually analizying the diagnosed conditions, it was observed that inflammatory and non-inflammatory fibrous hyperplasias (120 cases, 8.3\%), candidosis (77 cases, 5.3\%), periradicular inflammatory lesions (72 cases, $5.0 \%$ ), potentially malignant disorders (52 cases, 3.6\%), inflammatory periodontal diseases ( 49 cases, $3.4 \%$ ), injuries caused by external agents (48 cases, 3.3\%), mucous extravasation phenomena (48 cases, 3.3\%), carcinomas ( 36 cases, 2.5\%) and benign fibro-osseous lesions (23 cases, $1.6 \%$ ) represented the most common diagnosis.

The location of the lesions showed that the eight most common sites were the alveolar mucosa, gingiva, vestible and retromolar area, as a group ( 237 cases, $16.9 \%$ ), followed by the tongue (163 cases, $11.7 \%)$, lips (162 cases, $11.6 \%$ ), mandible (155 cases, $11.1 \%)$, buccal mucosa (120 cases, $8.6 \%)$, palate (118 cases, $8.4 \%$ ), teeth (111 cases, 7.9\%), and maxilla and maxillary sinus (102 cases, $7.3 \%$ ).
Table 1. Distribution of the 1444 final diagnosis in the 19 groups and per age group.

\begin{tabular}{|c|c|c|c|}
\hline Classification & $\mathrm{N}(\%)$ & $\leq 20$ years & $>20$ years \\
\hline Soft tissue tumors & 184 (12.7\%) & 24 (13\%) & $160(87 \%)$ \\
\hline Developmental defects & $161(11.2 \%)$ & $15(9.3 \%)$ & $146(90.7 \%)$ \\
\hline Epithelial pathology & 127 (8.8\%) & 5 (3.9\%) & $122(96.1 \%)$ \\
\hline Salivary gland pathology & $125(8.6 \%)$ & 31 (24.8\%) & $94(75.2 \%)$ \\
\hline $\begin{array}{l}\text { Physical and chemical } \\
\text { injuries }\end{array}$ & 105 (7.3\%) & $9(8.6 \%)$ & 96 (91.4\%) \\
\hline $\begin{array}{l}\text { Pulpal and periapical } \\
\text { disease }\end{array}$ & 103 (7.1\%) & 20 (19.4\%) & $83(80.6 \%)$ \\
\hline Abnormalities of teeth & $93(6.4 \%)$ & 24 (25.8\%) & $69(74.2 \%)$ \\
\hline $\begin{array}{l}\text { Fungal and protozoal } \\
\text { infections }\end{array}$ & $80(5.5 \%)$ & 0 & 80 (100\%) \\
\hline Periodontal diseases & 68 (4.7\%) & $13(19.1 \%)$ & 55 (80.9\%) \\
\hline Bone pathology & 67 (4.6\%) & $8(11.9 \%)$ & $59(88.1 \%)$ \\
\hline $\begin{array}{l}\text { Facial pain and } \\
\text { neuromuscular diseases }\end{array}$ & $55(3.8 \%)$ & $2(3.6 \%)$ & 53 (96.4\%) \\
\hline $\begin{array}{l}\text { Odontogenic cysts and } \\
\text { tumors }\end{array}$ & $50(3.5 \%)$ & 20 (40\%) & 30 (60\%) \\
\hline Dermatologic diseases & 39 (2.7\%) & $1(2.6 \%)$ & 38 (97.4\%) \\
\hline $\begin{array}{l}\text { Allergies and } \\
\text { immunological diseases }\end{array}$ & $33(2.3 \%)$ & $2(6.1 \%)$ & 31 (93.9\%) \\
\hline Viral infections & $30(2.1 \%)$ & $6(20 \%)$ & $24(80 \%)$ \\
\hline Bacterial infections & $15(1.0 \%)$ & $6(40 \%)$ & $9(60 \%)$ \\
\hline Hematologic disorders & $10(0.7 \%)$ & 0 & $10(100 \%)$ \\
\hline $\begin{array}{l}\text { Oral manifestations of } \\
\text { systemic disease }\end{array}$ & $7(0.6 \%)$ & $2(28.6 \%)$ & $5(71.4 \%)$ \\
\hline Others & 92 (6.4\%) & $11(12 \%)$ & $81(88 \%)$ \\
\hline Total & 1444 (100\%) & $199(13.8 \%)$ & $1245(86.2 \%)$ \\
\hline
\end{tabular}

\section{DISCUSSION}

The present study aimed to show the frequency of oral diseases diagnosed in a cohort of patients attending on an Oral Medicine service in Brazil during a 7-year period. These patients were mostly referred for the clinic from public dental and medical services or from other clinics from the Dental School for diagnosis and treatment of oral and maxillofacial diseases. Although such studies are essential to evaluate the differences and similarities in geographic and populational distribution of oral diseases, comparison between different studies is often difficult and laborious, as they usually show different methodological assays.

The origin of the sample is a crucial point in comparing the results from epidemiological studies. Several studies have been conducted with population-based samples ${ }^{1-5,8}$ and these will probably show different results when compared to studies conducted at universities and centers of specialized health care, with individuals searching for assistance (convenience samples) ${ }^{6,9-13}$. 
Studies conducted in dental schools, both with patients in routine dental treatment or referred for stomatological evaluation, in spite of probably showing a different picture from the general population, may better represent a model of what occurs in daily practice of the profession ${ }^{6,11-14}$. In contrast, studies with samples derived from oral surgical pathology laboratories do not evaluate the frequency of clinically diagnosed lesions, basing their results on diseases diagnosed and/or treated by surgical procedures ${ }^{15,16}$.

Studies selecting populations by age group provide highly specific information, therefore, need to be analyzed separately. Studies conducted on samples composed of adults and elderly patients, for example, show a higher frequency of denture-related disorders, tobacco-related disorders and chronic traumatic conditions ${ }^{5,8,14,17-19}$, while studies using samples derived from children and adolescent groups show a higher frequency of developmental defects, such as geographic tongue, and physical injuries, such as biting and traumatic ulcers of the mucosa, recurrent aphthous stomatitis and infections, such as candidosis and herpetic lesions $s^{4,10,13,20}$.

The group of diseases considered by each study also directly influence the frequencies reported. Some studies did not consider developmental defects in their clinical evaluation, probably due to the difficulties in diagnosing early and discrete cases and to the high frequency of unnoticed alterations diagnosed during clinical examination, but the fact is that they create significant biases in their results, difficulting comparisons with other studies ${ }^{5,18}$. Several difficults can be also observed in studies that have included diagnosis derived from surgical pathology analysis ${ }^{5,6,12}$. Another important detail that should be always taken in account when comparing the frequency of oral diseases is wheter the authors have considered a final diagnosis only with the presence of clinical lesions or if they included diagnosis obtained by clinical history alone (i. e., recurrent aphthous stomatitis) ${ }^{9}$. These biases do not apply for all lesions diagnosed only by history and clinical examination, as some of them are essentially characterized by absence of clinical visible alterations, such as burning mouth syndrome.

The different professionals involved in the clinical examination in each study (dental students, clinical dentists, oral surgeons, maxillofacial surgeons, specialists in oral medicine and/or oral pathology, physicians) may also directly influence the results $3,4,10,14,19$. Population-based studies, for example, are essential as they can report the frequency of oral and maxillofacial diseases in large cohorts, but they are characterized by the difficulties in controlling calibration of the participants ${ }^{11}$. Our study focused in reporting the prevalence of oral and maxillofacial diseases in patients attending a Stomatology service supervised by the same two professionals specialized in Stomatology and Oral Medicine, who have worked together for the last 9 years, including the period of the study. This calibration helps in standardyzing the diagnostic protocols and would probably bring a more homogeneous profile to the reported sample, also avoiding the limitation of different diagnostic criteria that could have been previously used when dealing with retrospective cross-sectional studies.

The heterogeneity of social influences, harmful habits and social needs of each population can also modulate the results of the reported studies. Brazilian population is highly heterogeneous and any attempt to compare the real racial distribution of any disease would be challenging and would probably not reflect the true distribution in the population. Mathew et al. ${ }^{12}$ and Lin et al. ${ }^{21}$ investigated populations that have the social and cultural habit of betel chewing, which would justify the higher frequency of oral potentially malignant disorders. Harmful habits in our sample included mainly smoking and drinking habits but, as a retrospective study, we could not find comparable information from all clinical charts and decided not to include distribution of the lesions according to habits to avoid any biases in results.

As exposed above, data on the prevalence of oral and maxillofacial diseases derived from studies including patients attending specialized Stomatology clinics and with standardized methods are scarce, making it difficult to compare results of this study with other similar epidemiological studies. We can add to the heterogeneity of the methodological assays, for example, the distinct criteria used for diagnosing and classifying the diseases. In order to reduce this influence, our results were based on an international teaching reference in Oral Medicine and Oral Pathology ${ }^{7}$ for diagnosis and classification of the conditions. This method also allows the reproducibility of the diagnostic criteria and classification of the diseases with other for thcoming studies. Despite it, some few modifications were necessary to adjust this classification to the most current and accepted literature in this field. The use of an international reference on the field also permit not only to compare the most prevalent groups, but also to visualize what conditions are included in each individual group, facilitating the comparison and discussion of the described findings from each study.

Our results showed that the most common group of lesions included the soft tissue tumors, representing $12.7 \%$ of the total sample. The high frequency of lesions from this group is understandable because most oral exophytic hyperplastic soft-tissue growings, such as fibrous hyperplasias and pyogenic granulomas are included in this group. Our findings were somewhat lower than the results found by Espinoza et al. ${ }^{8}$ (16.1\%) and Mujica et al. ${ }^{18}$ (18\%), but significantly higher than those found by Dundar and Ilhan $\mathrm{Kal}^{14}(5 \%)$.

Developmental defects represented $11.2 \%$ of the total sample. Epidemiologic studies that do not consider these 
alterations as part of their sample do not allow evaluation of their frequency in comparison to other oral and maxillofacial diseases $^{5,18}$. On the other hand, some studies have found that developmental defects represent up to $45 \%$ of all oral lesions, probably because they should have considered all developmental defects diagnosed in their patients, independently if they were or were not the patient's complaints or due to the younger age of the sample or additionally due to real true geographic variations ${ }^{10,12,13}$. Studies that include developmental defects when they are the chief complaint of the patients are important to visualize the representativeness of this group in the routine of an Oral Medicine clinic. Additionally, the tongue is the most common affected anatomic location in this group of alterations, which certainly contributed to the fact that the tongue was the second most common anatomic location of the diseases in the present sample.

Epithelial diseases accounted for $8.8 \%$ of our sample, similarly to Garcia-Polla Vallejo et al. ${ }^{1}(9.1 \%)$, but higher than Pentenero et al..$^{5}$ (3.5\%), Kovac-Kovacic and Skaleric ${ }^{9}$ (5.3\%) and Dundar and Ilhan Kal ${ }^{14}(6.5 \%)$. Potentially malignant disorders of the oral cavity and oral cancer are included within this group and represented together about $41 \%$ of all lesions diagnosed in our patients. These two subgroups represented together about $6 \%$ of all diseases diagnosed in the sample, being the third most frequent subgroup. These results are expected as Brazil shows one of the highest incidences of oral and oropharyngeal cancer in the world ${ }^{22}$.

Although most patients from this sample were adults, especially in their fifth and sixth decades, children and adolescents represented up to $17 \%$ of the patients. Epidemiological studies in this age group have demonstrated that the profile of diagnosed conditions is different from the adult distribution. All groups in our study predominantly affected adults, in special fungal and protozooal infections, especially due to candidosis and paracoccidiodomycosis (endemic to some regions in $\mathrm{Brazil}^{23}$ ), hematological disorders and skin diseases. Nevertheless, children and adolescents represented up to $40 \%$ of the affected patients in two groups: odontogenic cysts and tumors and bacterial infections. This distribution was expected due to the high number of dentigerous cysts, odontomas and keratocystic odontogenic tumors in the first group, and cervical tuberculosis in the second.

When evatuating the frequency of the most common diseases in the sample, it was observed that fibrous hyperplasias were the most common conditions, representing $8.3 \%$ of the total sample, in accordance with Espinoza et al. ${ }^{8}(9.4 \%)$ and Dundar and Ilhan Kal ${ }^{14}(5.1 \%)$ but much lower than the results from Mujica et al. ${ }^{18}$ (28\%). Candidosis was the second most common diagnosis, constituting $5.3 \%$ of the sample, similarly to the results of Dundar and Ilhan Kal ${ }^{14}(6 \%)$, but much lower than the results reported by Espinoza et al. ${ }^{8}$ (25\%), Reichart ${ }^{17}$ $(18 \%)$ and Mujica et al. ${ }^{18}(18 \%)$. These differences could be explained by the variability of diagnostic criteria used especially in denture-related atrophic candidosis. In addition to these two main groups described above, it is important to draw attention to the results of two other groups in the present study. First, as our study also included diseases affecting the hard tissues of the maxilla and mandible, periradicular lesions of inflammatory origin and odontogenic cysts and tumors proved to be an important component of the series. And second, the great frequency of oral potentially malignant disorders and oral cancer inside the group of epithelial diseases, as previously discussed. This reinforces the importance of outpatient services in Stomatology as one the most important strategies for diagnosing oral cancer and its precursor lesions.

\section{CONCLUSION}

Studies evaluating large series of patients attending on Oral Medicine services are able to show a specific profile of distribution of oral and maxillofacial diseases in a selected population. Results from the present study showed the characteristic distribution of these conditions in an urban area in the southeastern part of Brazil. Hopefully data derived from this study will add relevant information and will direct new strategies for oral lesions prevention and early diagnosis in the specific area of the study. Other studies with similar methods are encouraged to allow direct comparison on the prevalence of oral and maxillofacial conditions and to understand their true geographic and social diversity all over the world.

\section{ACKNOWLEDGEMENTS}

The authors wish to thank FAPERJ, Rio de Janeiro, Brazil, for research funding.

\section{REFERENCES}

1. García-Pola Vallejo MJ, Martínez Díaz-Canel AI, García Martín JM, González García M. Risk factors for oral soft tissue lesions in an adult Spanish population. Community Dent Oral Epidemiol. 2002;30(4):277-85. DOI: http://dx.doi.org/10.1034/j.1600-0528.2002.00048.x

2. Shulman JD, Beach MM, Rivera-Hidalgo F. The prevalence of oral mucosal lesions in U.S. adults: Data from the Third National Health and Nutrition Examination Survey, 1988-1994. J Am Dent Assoc. 2004;135(9):1279-86. PMID: 15493392

3. Mumcu G, Cimilli H, Sur H, Hayran O, Atalay T. Prevalence and distribution of oral lesions: a cross-sectional study in Turkey. Oral Dis. 2005;11(2):81-7. DOI: http://dx.doi.org/10.1111/j.16010825.2004.01062.x 
4. Parlak AH, Koybasi S, Yavuz T, Yesildal N, Anul H, Aydogan I, et al. Prevalence of oral lesions in 13- to 16-year-old students in Duzce, Turkey. Oral Dis. 2006;12(6):553-8. DOI: http://dx.doi. org/10.1111/j.1601-0825.2006.01235.x

5. Pentenero M, Broccoletti R, Carbone M, Conrotto D, Gandolfo S. The prevalence of oral mucosal lesions in adults from the Turin area. Oral Dis. 2008;14(4):356-66. DOI: http://dx.doi.org/10.1111/j.16010825.2007.01391.x

6. Cebeci AR, Gülşahi A, Kamburoglu K, Orhan BK, Oztaş B. Prevalence and distribution of oral mucosal lesions in an adult Turkish population. Med Oral Patol Oral Cir Bucal 2009;14(6):E272-7.

7. Neville BW, Damm DD, Allen CM, Bouquot JE. Oral and Maxillofacial Pathology. 3rd ed. St. Louis: Saunders Elsevier; 2009.

8. Espinoza I, Rojas R, Aranda W, Gamonal J. Prevalence of oral mucosal lesions in elderly people in Santiago, Chile. J Oral Pathol Med. 2003;32(10):571-5. DOI: http://dx.doi.org/10.1034/j.16000714.2003.00031.x

9. Kovac-Kovacic M, Skaleric U. The prevalence of oral mucosal lesions in a population in Ljubljana, Slovenia. J Oral Pathol Med. 2000;29(7):331-5. DOI: http://dx.doi.org/10.1034/j.16000714.2000.290707.x

10. Bessa CF, Santos PJ, Aguiar MC, do Carmo MA. Prevalence of oral mucosal alterations in children from 0 to 12 years old. J Oral Pathol Med. 2004;33(1):17-22. DOI: http://dx.doi.org/10.1111/j.16000714.2004.00200.x

11. Castellanos JL, Diaz-Guzmán L. Lesions of the oral mucosa: an epidemiological study of 23785 Mexican patients. Oral Surg Oral Med Oral Pathol Oral Radiol Endod. 2008;105(1):79-85. PMID: 17560136 DOI: http://dx.doi.org/10.1016/j.tripleo.2007.01.037

12. Mathew AL, Pai KM, Sholapurkar AA, Vengal M. The prevalence of oral mucosal lesions in patients visiting a dental school in Southern India. Indian J Dent Res. 2008;19(2):99-103. DOI: http://dx.doi. org/10.4103/0970-9290.40461
13. Majorana A, Bardellini E, Flocchini P, Amadori F, Conti G, Campus G. Oral mucosal lesions in children from 0 to 12 years old: ten years' experience. Oral Surg Oral Med Oral Pathol Oral Radiol Endod. 2010;110(1):e13-8. PMID: 20452255

14. Dundar N, Ilhan Kal B. Oral mucosal conditions and risk factors among elderly in a Turkish school of dentistry. Gerodontol. 2007;53(3):165-72.

15. Jones AV, Franklin CD. An analysis of oral and maxillofacial pathology found in adults over a 30-year period. J Oral Pathol Med. 2006;35(7):392-401 (a). DOI: http://dx.doi.org/10.1111/j.16000714.2006.00451.x

16. Jones AV, Franklin CD. An analysis of oral and maxillofacial pathology found in children over a 30-year period. Int J Paediatr Dent. 2006;16(1):19-30 (b). DOI: http://dx.doi.org/10.1111/j.1365263X.2006.00683.x

17. Reichart PA. Oral mucosal lesions in a representative cross-sectional study of aging Germans. Community Dent Oral Epidemiol. 2000;28(5):390-8. DOI: http://dx.doi.org/10.1034/j.16000528.2000.028005390.x

18. Mujica V, Rivera H, Carrero M. Prevalence of oral soft tissue lesions in an elderly Venezuelan population. Med Oral Patol Oral Cir Bucal 2008;13(5):E270-4.

19. Demko CA, Sawyer D, Slivka M, Smith D, Wotman S. Prevalence of oral lesions in the dental office. Gen Dent. 2009;57(5):504-9.

20. Shulman JD. Prevalence of oral mucosal lesions in children and youths in the USA. Int J Paediatr Dent. 2005;15(2):89-97. DOI: http:// dx.doi.org/10.1111/j.1365-263X.2005.00632.x

21. Lin HC, Corbet EF, Lo EC. Oral mucosal lesions in adult Chinese. J Dent Res. 2001;80(5):1486-90. PMID: 11437225 DOI: http:// dx.doi.org/10.1177/00220345010800052001

22. Warnakulasuriya S. Global epidemiology of oral and oropharyngeal cancer. Oral Oncol. 2009;45(4-5):309-16. PMID: 18804401

23. Carvalhosa AA, Borges FT, França DCC, Queiroz RR, Moimaz SAS, Garbin CAS. Paracocciodioidomycosis prevalence in a public laboratory of the Brazilian unified health system. J Oral Diag. 2012;1(1):31-5. 